\title{
A EXPLORAÇÃO DAS ÁGUAS SUBTERRÂNEAS NUMA FRAÇÃO DO ESPAÇO GEOGRÁFICO DE BELÉM COMO ALTERNATIVA AO SERVIÇO DE ABASTECIMENTO PÚBLICO E COMO POSSIBILIDADE AO ENSINO DE GEOGRAFIA
}

\begin{abstract}
Michel Pacheco GUEDES ${ }^{1}$ Shirley Capela TOZI ${ }^{2}$ Tuane Larissa Rosário de SOUSA ${ }^{3}$

\section{Resumo}

O presente artigo é resultado de uma pesquisa possibilitada por meio de um projeto de iniciação científica ligado ao Programa Institucional de Bolsas de Iniciação à Pesquisa Científica, Tecnológica e de Inovação (PIBICTIIFPA - Campus Belém), ocorrida no período entre 2016 e 2017. O projeto assumiu um caráter de pesquisa descritiva com base em pesquisa de campo cujo lócus ocorreu na cidade de Belém do Pará numa porção da Travessa Mariz e Barros (Estrella) cuja principal problemática era entender porque razão os condomínios fazem uso da água subterrânea? Assim, por meio do levantamento, realização de entrevistas, classificação, montagem e análise de banco de dados, revisão bibliográfica, aulas teóricas, oficinas num caráter de iniciação científica junto a uma bolsista do ensino médio integrado, tratou-se sobre uma abordagem associada ao ensino de geografia e aplicado aos recursos hídricos relacionada às águas subterrâneas dos condomínios de uma fração do espaço urbano de Belém. Constatou-se que a maior parte dos condomínios fazem uso de poços tubulares particulares como alternativa, econômica e de qualidade, ao abastecimento público e que trabalhar o tema "água" como instrumento no ensino de geografia se revelou apropriado para estabelecer as relações entre processos e fenômenos sociais ligado ao tema dos recursos hídricos.
\end{abstract}

Palavras-chave: Recursos hídricos. Águas subterrâneas. Geografia. Condomínios.

\begin{abstract}
The present article is result of a research made possible by a scientific project linked to the Institutional Program of Scientific, Technologic and Innovational Researching Initiation (PIBICTI-IFPA - Belém), at the period of 2016 and 2017. The project was a descriptive research based on field research, located in the city of Belem, in the State of Pará. In the portion of Mariz e Barros (currently, Estrella) street, whose main problem was to understand "why the buildings make usage of subterranean water?" That way, through survey, interviews, classification, mounting and analysis of database, literature review, theoretical classes, scientifically initiative workshops with a scholarship student from the Integrated Secondary Education, we treated about an approach associated to the teaching of geography and applied to the hydric resources - related to the subterranean waters from the buildings of a fractional urban space of Belém. We have concluded that the widestpart of the buildings from Belém makes usage of private tubular wells as an economic and qualitative alternative to the public supply andthat it was very appropriate to work the theme "water" as an instrument of teaching of geography for establishment of relations between social processes and phenomena linked to the hydric resources.
\end{abstract}

Keywords: Hydric Resources. Subterranean Waters.Geography, Condominiums.

\footnotetext{
${ }^{1}$ Grupo de pesquisa SABERES GEOGRÁFICOS: DIÁLOGO ENTRE ENSINO, PESQUISA E EXTENSÃO (IFPA Campus Belém), Grupo de Pesquisa em Geografia das Águas da Amazônia (GGAM/FGCUFPA) e UNIVERSIDADE DO ESTADO DO PARÁ (UEPA).E-mail: michel.guedes@ifpa.edu.br ${ }^{2}$ Grupo de pesquisa SABERES GEOGRÁFICOS: DIÁLOGO ENTRE ENSINO, PESQUISA E EXTENSÃO (IFPA Campus Belém), Grupo de Pesquisa em Geografia das Águas da Amazônia (GGAM/FGCUFPA) e IFPA Campus Belém. E-mail: shirleytozi@ yahoo.com.br

${ }^{3}$ Bolsista PIBICTI//IFPA Campus Belém.
} 
Michel Pacheco GUEDES; Shirley Capela TOZI; Tuane Larissa Rosário de SOUSA

\section{INTRODUÇÃO}

Segundo a Organização das Nações Unidas para a Educação, a Ciência e a Cultura UNESCO/ONU, em relatório divulgado em 2006, 1,1 bilhão de habitantes têm problemas de acesso à água. Há quem considere que este problema esteja condicionado ao elevado crescimento populacional mundial, mas concordamos com os argumentos de Ribeiro (2008, p.19), que explica que nos países com baixa renda o consumo de água vem aumentando de acordo com o aumento da renda da população e acelerada urbanização.

Desde 2008 a cidade de Belém do Pará sofre com o chamado "boom da Construção Civil”. Neste contexto, de construções de edificações que tomou conta da paisagem da cidade, é oportuno refletirmos a partir de cada edificação construída, onde um novo Condomínio se ergue e, consequentemente, absorverá em seu quadro funcional, zeladores, administradores e síndicos. Nossa nossa primeira inquietação é: como será que estes profissionais estão gerindo em termos de qualidade e quantidade os recursos hídricos no trato com as águas subterrâneas, advindo da instalação de poços tubulares no seu interior? Levando-nos a refletir: a explotação de água subterrânea pelos Condomínios é uma fonte alternativa ao abastecimento urbano?

A cidade de Belém, por meio de seu desenho urbano, é delimitada pelas águas., Estando banhada ao Sul pelo Rio Guamá (que na sua foz mede entre 1.360 e $2.000 \mathrm{~m}$ de largura), e a ao Norte pelo Furo do Maguari, e a Oeste pela Baía do Guajará (possui em torno de 3 a 4 km de largura) e a Leste pelo município de Ananindeua.

O município de Belém possui atualmente 14 (quatorze) Bacias Hidrográficas sendo: Bacia do Outeiro, Bacia do Ananin; Bacia do Paracurí, Bacia do Ariri, Bacia do Mata Fome, Bacia de Val de Cães, Bacia do Una, Bacia do Murutucum, Bacia do Aurá, Bacia do Tucunduba, Bacia da Estrada Nova, Bacia do Reduto, e Bacia da Tamandaré.

Esse contexto hidrográfico confere à cidade de Belém a importância na sua relação geográfica com as águas. Todavia, nossa abordagem se dará sobre esse "espaço hídrico" no sentido dessa água subterrânea e os objetos técnicos ${ }^{4}$ a ela relacionados, que, captada por meio da Técnica, circula pelos sistemas particulares dos Condomínios de cidade.

Existe um conjunto de trabalhos que apontam a preocupação com a qualidade das águas subterrâneas na cidade de Belém, como: Uhly, 2004; Matta, 2009, Cabral \& Lima

\footnotetext{
${ }^{4}$ Objeto Técnico - "Será todo objeto - todo objeto suscetível de funcionar, como meio ou resultado, entre requisitos de uma atividade técnica (SANTOS, 2012, p.38)
} 
Michel Pacheco GUEDES; Shirley Capela TOZI; Tuane Larissa Rosário de SOUSA

2005, sobretudo, aquelas que fazem uso de poços tubulares com até $25 \mathrm{~m}$ de profundidade,. Todavia, poucos fazem referência ao uso em si dessa modalidade, de acesso a água captada pelas edificações, ou buscam entender o porquê da explotação das águas subterrâneas pelos Condomínios.

O desafio posto no presente trabalho, se dá a partir da grande dificuldade da associação do subtema dos Recursos Hídricos (RH's"), agregado as categorias geográficas, seja pelo caráter ainda considerado novo no âmbito da Geografia, embora, outros autores, como Bordalo(2006), Tozi(2009), Ribeiro(2008) e Guedes(2016) já venham se desdobrando nesta problematização. Todavia, descrever, analisar e apresentar estes resultados nesta pesquisa sobre o temas dos RH's, agregado à Geografia, tornou-se uma provocação ainda maior.

Assim, pelo viés da ciência geográfica, fazemos uma análise fundamentada na categoria "Espaço Geográfico", com base teórica em Milton Santos (1926-2001), dentro de um contexto e perspectiva que relaciona, revela e aponta tendência no trato do uso das águas subterrâneas, como alternativa ao serviço de abastecimento público, ofertado na cidade de Belém (PA), via Companhia de Saneamento do Pará.

Assim, a problematização da pesquisa partiu da seguinte inquietação: os Condomínios de Belém fazem uso adequado da água subterrânea? Pela qual nossas hipóteses supuseram: a) Os Condomínios utilizam água subterrânea de poços tubulares por razões de ordem econômica ou de qualidade? b) Os poços presentes nos Condomínios são de tipologia artesiano ou tubulares? c) Existe uma preocupação por partes dos Condomínios quanto à manutenção e limpeza dos poços, como rege a chamada "Lei da Caixa d'água, haja vista que em Belém, existe uma legislação específica que trata da obrigatoriedade da realização da limpeza dos reservatórios superiores (caixas d'água) e inferiores (cisternas), por partes dos Condomínios, a cada quatro meses, previsto em lei municipalno 8740, de 19 de maio de 2010, conhecida por muitos, como a "Lei da Caixa D’água”?

\section{A ÁGUA ENQUANTO OBJETO TÉCNICO}

Embasados em Santos (2012), na sua preocupação de inserir a Técnica no debate geográfico, este resolve igualar a ideia de "meio", algo como a inclusão do homem em um novo meio natural (Santos, 2012, p.38). água, pode ser considerada um objeto natural e pode 
Michel Pacheco GUEDES; Shirley Capela TOZI; Tuane Larissa Rosário de SOUSA

também ser um "objeto técnico neste contexto, em vista das diversas facetas que "a água" assume. Afinal, água não é tão somente água simplesmente todo tempo e todo instante, depende muito de seus usos no tempo e no espaço, pois, existe uma polissemia no trato dos inúmeros conceitos relacionados a água (RAVENA, 2012, p.60).

Assim, Séris (1994, p. 24, apud Santos, 2012, p.38) diz que: "será objeto técnico todo objeto suscetível de funcionar como meio ou resultado, entre requisitos de uma atividade técnica", Logo, desde a captação (explotação) da água subterrânea e todo seu ciclo dentro de uma unidade condominial, ela, dentro desse sistema e pela natureza de seu uso para o abastecimento humano e outros usos, dependendo da tipologia de Condomínio (Residencial, comercial ou misto), passando por um complexo sistema técnico (rede de tubulações, cisternas, reservatórios superiores, movimentando seu fluxo com base em energia elétrica ou gravitacional, etc), confere à água o seu caráter de objeto técnico.

Por que não dizer que a água, integrante dentro de uma fração do solo urbano, onde temos uma organização social estruturada horizontalmente, numa escala de cidade como Belém, marcada por um densa urbanização e verticalização, temos a presença de uma introdução de objetos técnicos ou rede socieotécnica (SANTOS, 2012, p.39),relacionadas aos usos das águas subterrâneas, que, portanto, estão contribuindo para a produção do meio geográfico, pois, se torna impossível uma edificação por menor que seja, sem o mínimo de um sistema de abastecimento de água.

\section{ÁGUA SUBTERRÂNEA TAMBÉM É UM RECURSO NATURAL FINITO}

Água é um bem natural essencial à vida, porém, enquanto recurso natural, à percepção de Simonian (2000): "recursos naturais entende-se aqueles que são dados pela natureza, os quais passam por processos contínuos de transformações, inclusive com a participação dos seres humanos". Considerando esse contexto, segundo Becker (2003), faz um tempo que ocorre a mercantilização dos elementos da natureza, chamados por ela de "mercadorias fictícias", assim como a "terra", o "ar" e agora com a "água" ao mesmo tempo, de acordo com a classificação de Setti, (2001), em "campos de atividades correlatos aos recursos hídricos", citando Barth (1997, apud SETTI, 2001): relacionando atividade versus recursos hídricos.

Portanto a água é considerada, enquanto "recurso natural" (atividade) e mineral (recurso hídrico) no caso das águas subterrâneas, explicitando uma relação entre os 
Michel Pacheco GUEDES; Shirley Capela TOZI; Tuane Larissa Rosário de SOUSA

conhecimentos envolvidos em atividades que envolvem a gestão da água, ao mesmo tempo em que Ravena (2003), citada por Castro (2003), utiliza-se da expressão pool resourcestratando a água enquanto recurso natural, especialmente a subterrânea (RAVENA, 2003 apud CASTRO, 2003).

\section{A ÁGUA E O ENSINO DE GEOGRAFIA}

As possibilidades são inúmeras ao se trabalhar o tema "água", associado ao ensino da Geografia, seja enquanto ciência intimamente atrelada às disciplinas de Hidrografia, Hidrologia, Geomorfologia Fluvial. Ainda, pelo caráter polissêmico que a "água" em si assume, ora como recurso hídrico, ora como bem de consumo massivo, ora como sua perspectiva ambiental, ora utilitário, simbólico, além de inúmeras abordagens de ordem interdisciplinar como a "água" em si sugere, atrelada à possibilidade multidisciplinar que é próprio da Ciência Geográfica.

Em se tratando de Geografia, há uma lacuna nesta ciência sob seu casamento com o tema dos RH's, denotando tanto para quem pesquisa quanto para quem ensina, uma grande dificuldade em associá-lo em suas categorias geográficas específicas de análise, embora, alguns autores tenham feito com certo sucesso, como Bordalo (2006), Ribeiro (2008), Tozi (2009) e Guedes (2016). Todavia, nesse universo, poucos conseguem o debruçar necessário para fazer as devidas análises e amarrações.

Ao tratarmos do tema da "água" neste projeto, esta nos permitiu não somente pelo seu caráter transversal, como também ligando-a à dimensão ambiental, previstos desde os PCN's para os níveis fundamental e médio surgidos desde 1998, de modo que, agregá-la ao ensino de geografia mais do que ser uma orientação verticalizada, também, revelou-se com uma grande possibilidade de oferecer ao aluno, (neste caso, a bolsista envolvida), uma visão de totalidade e integração do tema água com os demais temas, integrando a geografia como: recursos naturais, bacia hidrográfica, gestão e gerenciamento, técnica, etc, especialmente como nos dizeres de Castellar (2013,p.14) apudBertir (2016, p.21), “...mas no ensino de geografia, basta saber ler e escrever: é preciso ir além e sim compreender as relações existentes entre os fenômenos que estão sendo analisados...”.

Assumindo os RH'senquanto instrumento de ensino, consideramos que issonos exige, enquanto professores ou pesquisadores, também uma abordagem, uma compreensão e uma 
Michel Pacheco GUEDES; Shirley Capela TOZI; Tuane Larissa Rosário de SOUSA

intervenção, interdisciplinar e multidisciplinar. Esse modo de ver nos concede um conjunto de possibilidades para tratar do tema sob os mais variados contextos e aplicabilidades. Por essa razão, os recursos hídricos (RH's) tem sido eixo de abordagem desse trabalho.

Noutro aspecto, tratar do tema "água" sob uma perspectiva da realidade local, também tem se mostrado um desafio e por muitas vezes, inovador, uma vez que, fazer uma geografia para além da sala de aula, inserido num ambiente altamente urbanizado, que é o contexto das IES aqui envolvidas nesta pesquisa, tem-se mostrado de frágil aplicabilidade pelos alunos da teoria versus prática dentro de um contexto de Amazônia com suas especificidades locais, mas, facilmente absorvida pela bolsista orientada sob essa perspectiva "água" e "gestão"; "abastecimento" e "Condomínios", adotados neste trabalho.

A geografia “das salas de aulas" está, justamente, teórica e descritiva, numa distorção da etimologia da palavra "Geografia", tal como se provocam nessa reflexão:

\footnotetext{
"ao trabalhar diretamente com professores em sala de aula, verificou que eles partem sempre da leitura de texto de um livro didático, sendo raras as aulas que se iniciam com leitura de um jornal ou revista. Quando fazem uso da realidade dos alunos, limita-se a descrevê-la”. (GEBRAN, 1990, apud STRAFORINI, 2008, p.67.)
}

Nosso ponto de diretriz é o entendimento de CALVACANTI (2017, p.67) que "o ensino é a construção de conhecimento pelo aluno" corroborando quando ela complementa: "O aluno é sujeito ativo do seu processo de formação e de desenvolvimento intelectual, afetivo e social, o professor tem o papel de mediador do processo de formação do aluno" e, por essa razão, é preciso tirá-lo da sala de aula e levá-lo a sua própria realidade local, para que essa mediação seja entre o teórico versus a realidade.

Nesta mesma linha, Jakcs Richard de Paulo (2016), enfatiza dizendo "que o ensino de Geografia tem o papel primordial: corroborar a compreensão do espaço geográfico e relacionar as interações quanto às questões sociais, culturais, políticas, econômicas e ambientais, ou seja, a organização" Paulo (2016, p.26). Otema "água" e suas vertentes, associadas ao ensino de geografia, revelou-se neste trabalho com uma grande possibilidade de estabelecer de maneira coerente esta aplicabilidade. 
Michel Pacheco GUEDES; Shirley Capela TOZI; Tuane Larissa Rosário de SOUSA

\section{OS CONDOMÍNIOS E O SISTEMA DE AÇÕES}

Desde 1997, por meio da Lei 9.433 de 8 de janeiro de 1997, foi promulgada no Brasil a chamada "Lei das Águas", materializando pelo ordenamento jurídico a preocupação no acesso a água enquanto recurso natural finito. Essa se preocupação se justificou pela rapidez na degradação dos RH's em termos de qualidade e quantidade, causado pelo uso desenfreado desse recurso natural, tido por muito tempo como inesgotável, apontando uma tendência que nos dizeres de Ribeiro (2008), "água é fonte de riqueza e de conflitos” (RIBEIRO, 2008, p.17).

Pelos motivos acima expostos, cabe também à Geografia a identificação, leitura e uma abordagem a partir de suas categorias que nos leve a refletir os diversos usos das águas na contemporaneidade. Naquilo que já no provocara o geógrafo Claude Raffestin (1993):

Quando o geógrafo é posto diante de um sistema territorial, ele descobre uma produção já elaborada, já realizada. Produção suscetível de mudanças, contudo suficientemente fixa para ser analisada. Mas, toda análise supõe uma linguagem. Sem linguagem, não há leitura possível, não há interpretação e, portanto, nenhum conhecimento sobre a prática que produziu o território (RAFFESTIN, 1993, p.153).

Embora, não estejamos nos aprofundando sobre a categoria geográfica Território, ainda assim, tanto Território quanto o Espaço se adequam à ideia de RH's, haja vista que, o Território em si, por estabelecer relações intrínsecas de poder, ele é fruto de práticas, comportamentos e relações estabelecidas por um grupo de atores. Já este ensaio embasa-se noutra categoria geográfica, denominada Espaço Geográfico, que nos próprios dizeres do Geógrafo Claude Raffestin: "É essencial compreender bem que o espaço é anterior ao território" (RAFFESTIN, 1993, p.144).

Porém, neste artigo tangenciando pela perspectiva geográfica, adotou-se as premissas presentes na análise da categoria Espaço Geográfico e, assim, partimos da premissa de Milton Santos (1926-2001), sobre o quanto a sua concepção da construção dessa categoria apropriada pela Geografia.

O nosso ponto de partida é quando para este autor, enquanto ele que ele denomina "configuração territorial" ou "configuração geográfica" que ao diferir do "espaço", é formada pelo "conjunto de formado pelos sistemas naturais existentes em um dado país ou numa dada área e pelos acréscimos que os homens superimpuseram a esses sistemas naturais" (SANTOS, 2012, p.662). 
Michel Pacheco GUEDES; Shirley Capela TOZI; Tuane Larissa Rosário de SOUSA

Assim, pela presença de aquíferos subtérreos no Brasil, entre eles o "Aquífero Guarani" e na Amazônia do aquífero "Alter do Chão", por serem os maiores reservatórios de água subterrânea do planeta e adicionando a existência neste espaço amazônico do maior reservatório de água doce no estado líquido da Terra e a maior bacia hidrográfica em extensão e volumes d'água do mundo, esse conjunto de "sistemas territoriais", a partir do advento da Técnica nos oferta uma condição natural favorável a instalação, captação, explotação e uso da água subterrânea como fonte de abastecimento de água dos agrupamentos humanos residentes nas edificações, ou seja, a "configuração territorial" concebida pela sua existência material própria, todavia, somente a partir da "existência social"que ela é obtida mediante as relações sociais.

Logo, considerando que, a Técnica é "um conjunto de meios instrumentais e sociais, com os quais o homem realiza sua vida, produz e, ao mesmo tempo, cria espaço." (SANTOS, 2012, p.29), a obtenção de um serviço ou modalidade de acesso à água para abastecer uma edificação é resultante dessas relações sociais, haja vista que, é o homem fazendo e (re) criando formas de acesso à água pelo instrumento de um poço tubular ou seu acesso à rede de abastecimento, oferecido pela companhia de abastecimento de água. Portanto, por esse razão, o objeto de análise desta pesquisa teve como foco a identificação de qual sistema de abastecimento de água (obra ou prótese) é utilizado pelas edificações.

O Espaço Geográfico da cidade de Belém, no contexto desse trabalho aqui representado pela fração da Travessa Mariz e Barros no bairro do Marco (entre Av. Almirante Barroso e Av. Rômulo Maioriana), é compreendido como um "conjunto indissociável, solidário e também contraditório de sistemas de objetos e sistema de ações" (SANTOS, 2012 p.63), agora, marcados pelos objetos técnicos ou as redes de abastecimento superficial e subterrânea de água, ou os "acréscimos" dotados de conteúdo técnicos.

Mergulhados na concepção do "sistema de ações" de Santos (2012), este considera a ação um processo que, devidamente projetado sobre um ato em si, visa à modificação de uma dada situação ou coisa, uma vez que, toda ação tem em si um propósito e realiza-se por um agente (ator social), podendo ser subordinada às normas escritas (formais) ou não (informais). Toda ação, pressupõe um movimento e um gasto de energia para movimentá-la.

Quando os Condomínios realizam uma "ação(ões)", no sentido de movimentar-se contra o serviço público de abastecimento, esse "conjunto de ações" referem-se à opção pelo acesso à água por meio de poço tubulares particulares, causando uma modificação da "coisa" 
Michel Pacheco GUEDES; Shirley Capela TOZI; Tuane Larissa Rosário de SOUSA

em si, produto desse "ato", alterando a ordem daquilo que está juridicamente estabelecido e cujo (os) propósito(s) se refletem num ato de protesto em melhoria na "qualidade" do serviço de abastecimento de água.

Quando se percebe esse "movimento" em relação a mais de uma "Edificação", estes acabam sendo frutos de um processo e subprocessos, resultando em "atos consecutivos", conforme teoriza SANTOS (2012, p.78-83). Assim, não estaria os demais Condomínios de Belém revelando uma tendência de uso de poços tubulares, de um "período inicial (completo) ou inserido num período intermediário causal (não completo e incompleto), sendo este parte condicionada a toda "ação" como um "Bem estreito", ou seja, produto fruto desse processo da ação por parte das edificações, uma vez que, essas ações podem estar se repetindo para outras frações do solo e subsolo de Belém?

Dentro dessa perspectiva de Milton Santos, este considera que dentro do "sistema de ações" existem três possibilidades, a) o agir técnico; b) o agir formal e o c) agir simbólico (este não será tratado aqui). O “Agir Técnico" são requeridas pelas técnicas enquanto o "Agir Formal" é obediente ao formalismo jurídico, considerando este autor que, em um dado momento uma dessas formas de agir(ação) uma triunfa sobre a outra.

Logo, do ponto de vista normativo ou "agir formal", numa cidade brasileira que disponha de um serviço público de abastecimento de água, seja dentro de um estado ou município, toda Condomínio (Edificação) é obrigado a ligar-se à rede da prestadora, ou seja, no caso da cidade de Belém, aonde passe a rede de abastecimento público disponível, o Condomínio é obrigado a conectar-se a esse sistema e, assim, regulamente, o Decreto Federal 7.217 de 21 de junho de 2010 que Regulamenta a Lei no 11.445 , de 5 de janeiro de 2007, que estabelece diretrizes nacionais para o saneamento básico, e dá outras providências: Art. $6^{-}$Excetuados os casos previstos nas normas do titular, da entidade de regulação e de meio ambiente, toda edificação permanente urbana será conectada à rede pública de abastecimento de água disponível. (Brasil, Decreto 7.217 de 21 de junho de 2010). Assim, uma das dimensões deste trabalho se refere ao ordenamento jurídico vigente, no que, se refere à diferenciação do que venha a ser edificação e Condomínio. Para ente fim, foram utilizados três (03) princípios jurídicos: 
Michel Pacheco GUEDES; Shirley Capela TOZI; Tuane Larissa Rosário de SOUSA

Tabela 1. - Princípios jurídicos adotados.

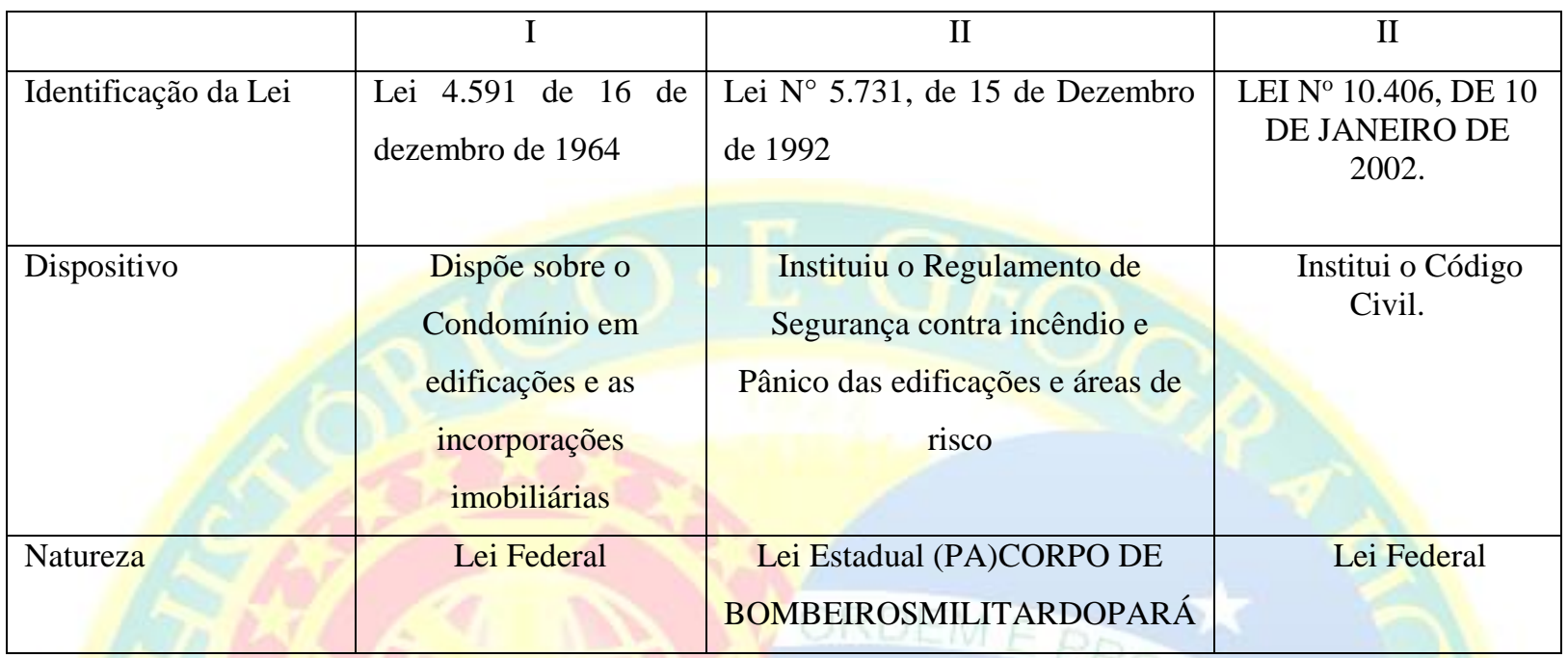

Fonte: os autores.

Quanto à tipologia das edificações (Condomínio) como parâmetro para identificação destes, foi utilizado o entendimento contido no Decreto $\mathrm{n}^{\mathrm{o}} 357$ de 21 de agosto de 2007 que Instituiu o Regulamento de Segurança contra incêndio e Pânico das edificações e áreas de risco para fins da Lei $N^{\circ} 5.731$, de 15 de Dezembro de 1992 e estabelece outras providências.

Assim, "Edificação" é a área construída, destinada a abrigar atividade humana ou qualquer instalação, não sendo considerado, todavia, para efeito desta normatização. Não são aplicadas às residências exclusivamente unifamiliares, com até dois pavimentos. , Assim, o presente trabalho considera apenas edificações ou Condomínios a partir de 03(três) andares:

$\S 4^{\circ}$ Estão excluídas das exigências deste Regulamento:

I - residências exclusivamente unifamiliares;

II - residências exclusivamente unifamiliares localizadas no pavimento superior de ocupação mista, com até dois pavimentos e que possuam somente acessos independentes. (CBPM-PA).

A Lei 4.591, de 16 de dezembro de 1964 que Dispõe sobre o Condomínio em edificações e as incorporações imobiliárias:

Art. $1^{\circ}$ As edificações ou conjuntos de edificações, de um ou mais pavimentos, construídos sob a forma de unidades isoladas entre si, destinadas a fins residenciais ou não-residenciais, poderão ser alienados, no todo ou em parte, objetivamente considerados, e constituirá cada unidade, propriedade autônoma sujeita às limitações da Lei.

$\S 1^{\circ}$ Cada unidade será assinalada por designação especial, numérica ou alfabética, para efeitos de identificação e discriminação. 


\section{Michel Pacheco GUEDES; Shirley Capela TOZI; Tuane Larissa Rosário de SOUSA}

$\S 2^{\circ}$ A cada unidade caberá, como parte inseparável, uma fração ideal do terreno e coisas comuns, expressa sob forma decimal ou ordinária.

Assim, um Condomínio é uma reunião ou comunhão de unidades autônomas e privativas, sujeito a áreas comuns e partes ideais, não pode ser confundido com uma personalidade jurídica, haja vista que, a regulamentação da referida Lei é estabelecida pelo Código Civil, por meio da Lei $N^{\circ} 10.406$, de 10 de Janeiro de 2002, onde estabelece que:

Art. 40. As pessoas jurídicas são de direito público, interno ou externo, e de direito privado.

Art. 44. São pessoas jurídicas de direito privado:

I - as associações;

II - as sociedades;

III - as fundações.

IV - as organizações religiosas; (Incluído pela Lei $n^{\circ} 10.825$, de 22.12.2003)

$\mathrm{V}$ - os partidos políticos. (Incluído pela Lei ${ }^{\circ} 10.825$, de 22.12.2003)

Ou seja, um Condomínio não se enquadra na modalidade de uma "pessoa jurídica" de direito público, interno ou externo, nem de direito privado, conforme destacado acima. Logo, para efeito deste trabalho, "Edificação" e "Condomínio" serão tratados como sinônimos. Outro viés de abordagem dessa pesquisa é pautado na defesa de uma corrente de estudiosos, sobretudo geólogos, que alegam que a exploração por meio dessa modalidade de captação do recurso natural subterrâneo, em face de sua disponibilidade hídrica.

Este processo é, economicamente, mais barata em relação à captação e tratamento em comparação as águas superficiais, haja vista, que a adoção pelo sistema subterrâneo importaria um custo de $30 \%$ mais barato, ainda assim, na hipótese levantada por Matta (2009), muitos Condomínios fazem uso dessa modalidade complementar de abastecimento como alternativa ao abastecimento público obrigatório, além de trabalhos que apontam a preocupação com a qualidade das águas subterrâneas na cidade de Belém, Uhly, 2004; Cabral \& Lima (2005).

Assim, o presente trabalho assumiu um caráter multidisciplinar, sustentando sobre quatro (04) perspectivas de abordagem: a) Ciências Jurídicas; b) Geologia e c)Geografia. 
Michel Pacheco GUEDES; Shirley Capela TOZI; Tuane Larissa Rosário de SOUSA

\section{PROCEDIMENTOS METODOLÓGICOS}

Pela ausência de uma literatura que pudesse fornecer dados descritivos dos Condomínios de Belém, quanto à categorização, quantificação, presença de poços tubulares ou não, a estratégia adotada foi a realização de três (03) macro momentos: a) aulas teóricas;

\section{b) Participação em palestras e oficinas, c) Trabalho de campo.}

O primeiro momento, o da teorização, serviu para nivelar a bolsista sobre a temática das águas subterrâneas e seus aspectos técnicos básicos (o que é um poço tubular; profundidade, captação, cisterna; reservatório superior) até a sua problematização quanto ao uso e qualidade da água, além da conceituação de Condomínio, haja vista que a literatura existente é demasiadamente técnica de um lado e de viés jurídico-administrativo de outro.

A segunda estratégia foi o envolvimento da bolsista em eventos, palestras e oficinas e contato com outro grupo de pesquisa (Grupo de Pesquisa em Geografia das Águas da Amazônia - GGAM - FGC-UFPA) que tratassem da problemática da água, pelo viés da Geografia, da Gestão e do Gerenciamento dos RH's, de modo a, auxiliá-la no universo complexo da temática e posterior aplicação nesta pesquisa.

A realização do trabalho de campo foi de fundamental importância para o desenvolvimento do projeto, justamente onde se buscou os dados primários, a partir da formulação, em conjunto com a bolsista, de um questionário semiestruturado e posterior visitas e entrevistas juntos aos Condomínios selecionados.

O recorte espacial se deu na travessa Mariz e Barros (atual Travessa da Estrella), entre a Avenida Almirante Barroso e a Travessa 25 de Setembro (Av. Rômulo Maiorana), no bairro do Marco e nosso universo foi extraído a partir do trabalho de Carvalho et.al (2015), que coletou para o bairro do Marco seis amostras pela qual, nesta pesquisa estavam previstos pelo menos três (03) Condomínios porém, chegamos a 05 unidades. Ainda, a escolha desse recorte se justifica quando este Projeto, quanto à sua natureza e proposta, ser uma ação de "extensão" e, com isso, foi escolhido Condomínios situados às adjacências do próprio IFPA Campus Belém. 


\section{RESULTADOS}

Um dos aspectos desta pesquisa foi à elaboração de um questionário semiestruturado, cuja, elaboração foi a partir do levantamento teórico e resultado das discussões. Foram elaboradas 32 perguntas, entre abertas e fechadas, distribuídas em seis (06) categorias de análise, de modo que se pudesse identificar o perfil do Condomínio, sua tipologia, cruzar e depurar esses dados, entre as categorias pesquisadas: a) Quanto a ocupação ${ }^{5}$ (residencial, comercial ou misto), quantitativo de apartamentos e andares; b)Função do entrevistado; c)

Molde de administração; d) Quanto ao uso e o sistema de abastecimento; e) Quanto ao conhecimento da legislação; f) Manutenção e Limpeza dos reservatórios.

Quadro 1 - Quanto às categorias de análise.

\begin{tabular}{|l|l|}
\hline ORDEM & \multicolumn{1}{|c|}{ CATEGORIAS DE ANÁLISE. } \\
\hline A. & Quanto à ocupação. \\
\hline B. & Função do entrevistado. \\
\hline C. & Molde de administração. \\
\hline D. & Quanto ao uso e osistema de abastecimento. \\
\hline E. & Quanto ao uso e o sistema de abastecimento. \\
\hline F. & Manutenção e Limpeza dos reservatórios. \\
\hline
\end{tabular}

Fonte: os autores.

Assim, dos 05 (cinco) edificações (Condomínios), visitadosna pesquisa , observou-se que, quanto à tipologia, são: 01 - misto; 4 residencial.

\footnotetext{
${ }^{5}$ XXXV - ocupação: é a atividade ou uso da edificação;XXXVI - ocupação mista: é a edificação que abriga mais de um tipo de ocupação - Lei $\mathrm{N}^{\circ}$ 5.731, de 15 de Dezembro de 1992.
} 


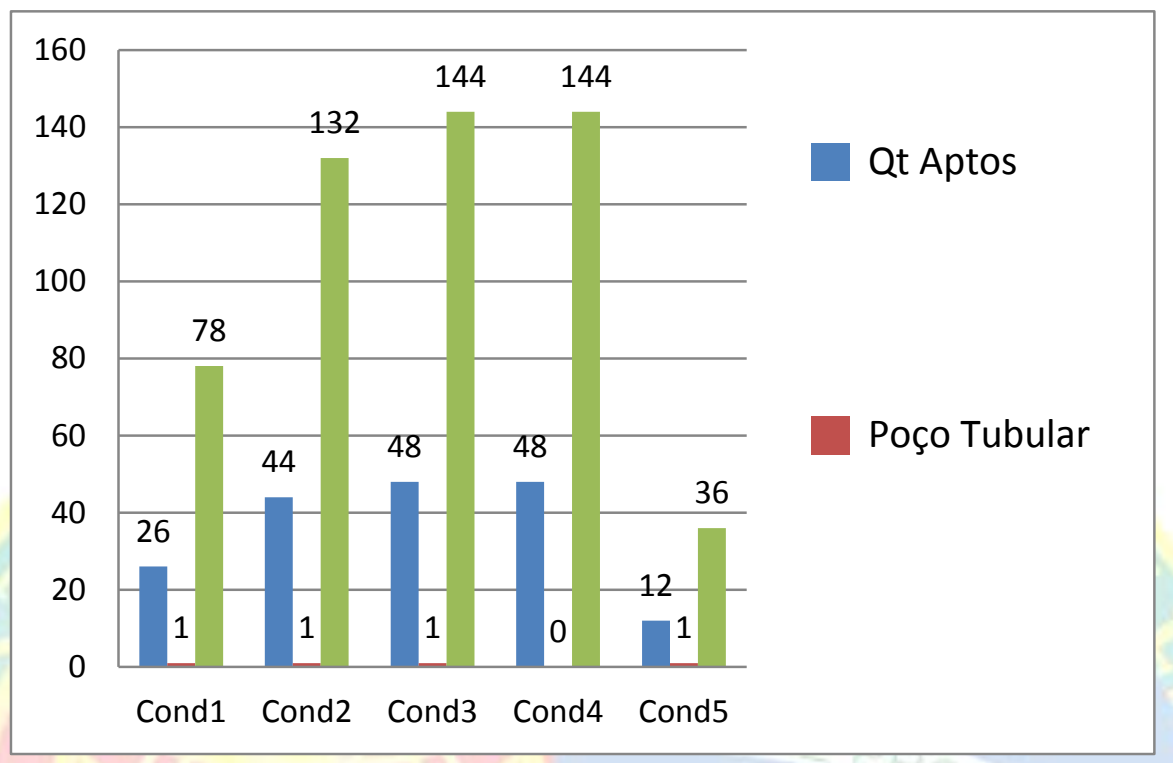

Gráfico1 - Perfil de ocupação Versus poços tubularesFonte: os autores.

Foi possível traçar uma relação entre a quantidade de unidades (apartamentos) e o uso de poços tubulares, importando que, dos cinco (05) visitados 04 (quatro) deles fazem de uso dessa modalidade de explotação de água. Quando relacionados a um quantitativo considerando um padrão de família de até três (03) pessoas, surge neste cruzamento o Gráfico 1 da relação de pessoas, atendidas pelo sistema subterrâneo versus o abastecimento público de água (COSANPA).

\section{QUANTO AOS MOLDES DE GESTÃO}

Fazendo um comparativo com a Tabela 2, adotando a equivalência que cada unidade (apartamento) consuma $200 \mathrm{l} / \mathrm{dia}^{6}$ (Neto, 2009) observa-se o volume ideal consumido de água por cada edificação na Tabela 2 numa variação entre 7.200 litros de água versus 28.800 litros por dia entre as edificações. Quanto à função do entrevistado, o primeiro a ser procurado era a figura do Síndico. Todavia, quase sempre esse ator é ausente no período diurno, onde na maioria das vezes este ter de exercer outra atividade remunerada, não era possível encontrá-lo na edificação, assim, a segunda pessoa a ser procurado era o Administrador ou Gerente

\footnotetext{
${ }^{6}$ Manual prático com fórmulas de saneamento básico - Neto. (2009, p.16) 
Michel Pacheco GUEDES; Shirley Capela TOZI; Tuane Larissa Rosário de SOUSA

Condominial, Zelador e o Porteiro nessa ordem, considerando o caráter hierárquico adotado num Condomínio, segundo CONVENÇÃO COLETIVA DE TRABALHO 2017/201972:

Quadro 2: ESTIMATIVA DO CONSUMO DE ÁGUA IDEAL - PESSOAS VERSUS LITROS DE ÁGUA DIA.

\begin{tabular}{|c|c|c|}
\hline \multicolumn{3}{|c|}{$\begin{array}{l}\text { ESTIMATIVA DOCONSUMO DE ÁGUA IDEAL - PESSOAS } \\
\text { VERSUS LITROS DE ÁGUA DIA. }\end{array}$} \\
\hline & FAMÍLIA PADRÃO X APTOS & ÁGUA 1/d \\
\hline Cond1 & 78 & 15.600 \\
\hline Cond2 & 132 & 26.400 \\
\hline Cond3 & 144 & 28.800 \\
\hline Cond4 & 144 & 28.800 \\
\hline Cond5 & 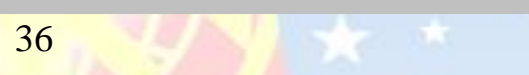 & 7.200 \\
\hline
\end{tabular}

Fonte: Os autores.

Quando os Condomínios realizam uma "ação (ões)", no sentido de movimentar-se contra o serviço público de abastecimento, esse "conjunto de ações" que se refere a opção pelo obtenção de água por meio de poço tubulares particulares, causa uma modificação da "coisa" em si, produto desse "ato", alterando a ordem daquilo que está juridicamente estabelecido cujo o propósito(s) se refletem num ato de protesto, em melhoria na "qualidade" do serviço de abastecimento de água, pois quando se perceber esse "movimento" em relação a mais de uma "Edificação" estes acabam sendo frutos de um processo e subprocessos, resultando em "atos consecutivos", conforme teoriza Santos (2012, p.78-83):

\footnotetext{
${ }^{7}$ Documento que regulamente as condições e o piso salarial do trabalhador em Condomínios. Disponível em: http://www.sindconpara.com.br 
Tabela 1 - Perfil dos entrevistados.

\begin{tabular}{|cc|}
\hline CATEGORIA & QUANTIDADE \\
\hline Síndico & 2 \\
Porteiro & 1 \\
Faxineiro & 1 \\
\hline
\end{tabular}

Fonte: Os autores.

É constatado no Gráfico 2, quanto à aplicação do "sistema de objetos" de Milton Santos, que quando o tratamento do "agir formal", mediante a Lei que determina a ligação na rede de abastecimento público vigente na cidade, esta triunfaria, uma vez que, estabelece essa obrigatoriedade. Porém, percebeu-se ao logo da pesquisa que nem todos os Condomínios da área estudada são ligados à rede pública de abastecimento, fazendo opção de outra e às vezes única fonte de abastecimento. Neste caso, o abastecimento subterrâneo e quando o "agir técnico" triunfou sobre o "agir formal”, segundo Milton Santos (2012).

Considerando, as Edificações "Cond2", "Cond3" e "Cond5", excluindo o Cond1" e "Cond4", o volume de água consumido totalizam $60.400 \mathrm{mil}$ 1/dia de água consumida para abastecer o equivalente a 312 apartamentos (unidades) que totalizam as três(03) Edificações dos cinco analisados, pois o "Cond4" faz uso do abastecimento público da COSANPA (Gráfico 2), enquanto o "Cond1” faz uso dos dois sistemas e não foi possível a determinação de como se divide o consumo dessa água. Quanto ao uso e o sistema de abastecimento: 
Gráfico 2 - TIPO DE ABASTECIMENTO DE ÁGUA

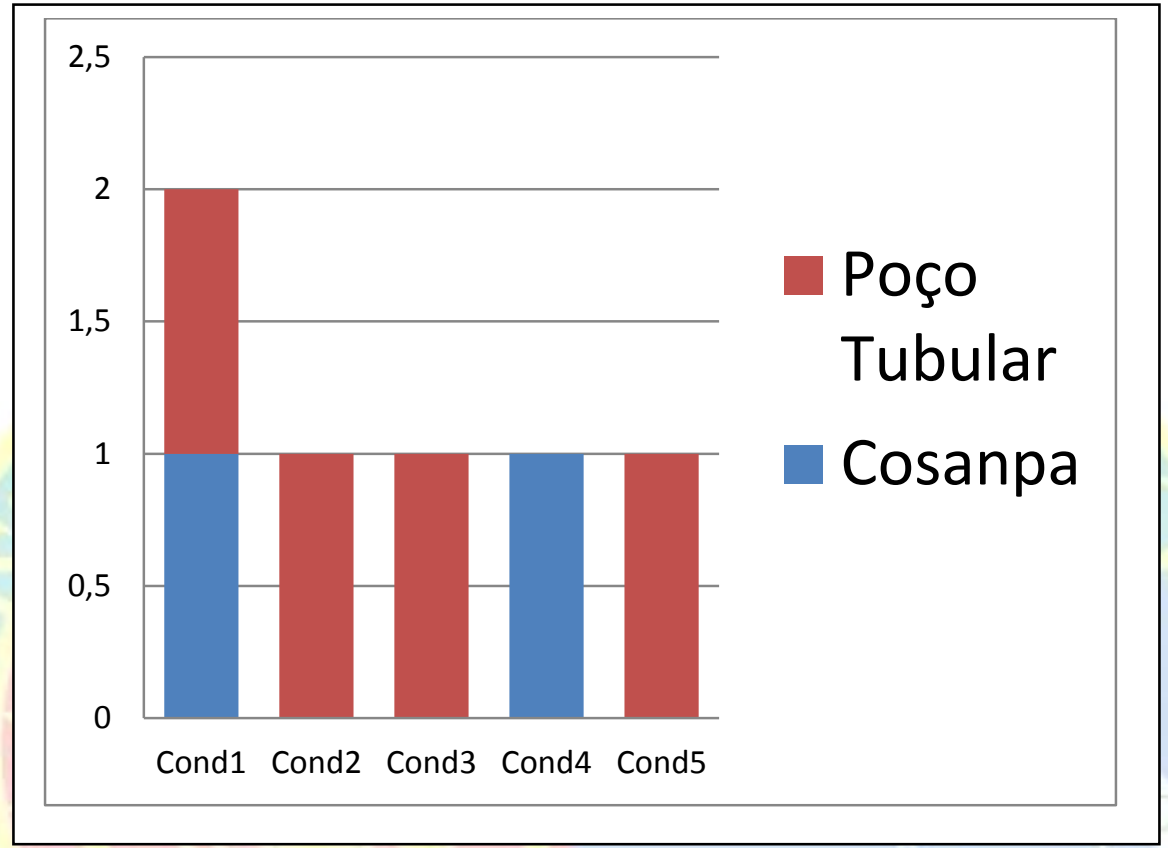

Fonte: os autores.

\section{CONSIDERAÇÕES FINAIS}

Quando a realidade exprime por meio do exercício teórico e científico um dado fenômeno ou processo, no contexto desse trabalho em espacial, temos um ponto de partida para ampliação dos nossos olhares e apreensão da própria realidade, que sabe assim, apontando tendência, o que é próprio da Geografia.

Quando percebemos o movimento de opção dos Condomínios e não se ligarem ao sistema de abastecimento público de água, via Companhia de Saneamento do Pará (COSANPA), seja pela alegação de "baixa qualidade" ou "interrupção contínua do serviço", isso remete a precariedade do serviço ofertado pela ótica dos condomínios presentes neste trabalho.

Esse processo parte do pressuposto que essa prática exercida pelos Condomínios de Belém pode estar se revelando uma problemática que porventura esteja se expandido por toda cidade, assim, como apontado para necessidade de observação e outras pesquisas que possam identificar a relação dos usos dos mananciais subterrâneos e seu devido comprometimento em termos de qualidade ou até de quantidade, uma vez que o uso não está sendo fiscalizado pelo 
Michel Pacheco GUEDES; Shirley Capela TOZI; Tuane Larissa Rosário de SOUSA

poder público para devida aplicação dos instrumentos normativos vigentes e nem há conhecimento da legislação eu rege a manutenção dos reservatórios de água superiores e inferiores e dos poços tubulares.

O viés da Técnica, por meio do conjunto, envolvendo meios instrumentais e sociais, seja pelas obras e equipamentos que são necessários para captar, transpor para um reservatório inferior (cisterna), elevar para um reservatório superior (caixa d'água), instalação de poços, exige um conjunto de conhecimentos, tecnicidade, desde a perfuração destes poços e da qualidade da água. Portanto, essa complexidade Técnica obriga que um Condomínio contrate um profissional habilitado para esse fim. Ainda assim, a manutenção e a limpeza de um poço tubular por aquelas pessoas que trabalham ou realizem a gestão num condomínio também se constitui de um conhecimento técnico relevante.

Porém, nenhum dos condomínios sequer tinha conhecimento da chamada "Lei da Caixa D'água" que os obriga e regularem esse tipo de manutenção, ou seja, o "agir formal" por parte dos Condomínios por mero desconhecimento revela-se um ato negligente pela ausência de uma melhor qualificação e informação dos funcionários destas firmas.

O caráter desta pesquisa, a partir de uma ação de iniciativa científica, revelou-se necessário à ampliação geográfica desta pesquisa, em termos dos usos, o que tem sido realizado com os recursos hídricos subterrâneos e leva-nos ainda a refletir como está sendo tratado o abastecimento de água paras as populações que moram em residências verticais em termos de quantidade e qualidade, especialmente, enquanto uma clara opção ao serviço público de abastecimento de água.

Se um Condomínio faz a opção por ter seu próprio uso particular de água, é com muita facilidade que discursos que defendam a privatização do serviço público de água venham ser uma opção que ganhem força sem o mínimo de reflexão entre os usuários ou ainda, aponta a atuação paralela da indústria ligada às águas subterrâneas atuando com o seu lobby, ou uma tecnoestrutura presente e marcante atuando na cidade, logo, um olhar mais apurado revela uma tendência de produção e transformação do meio geográfico, no que se refere ao uso e de como estão organizados no espaço os atores sociais, envolvidos na exploração da água subterrânea. 
Michel Pacheco GUEDES; Shirley Capela TOZI; Tuane Larissa Rosário de SOUSA

\section{REFERÊNCIAS}

BECKER, Bertha K. Inserção da Amazônia na Geopolítica da Água. São Paulo. 2003.

BELÉM Cidade das Águas. Joane Castro. Ed. Cabocla Produções. DVD. Col. 22 min. NAEA/ UFPA, 2003.

BERTIR. Marta. A formação de professores dos anos iniciais da educação básica; contribuições para o ensino de geografia. IN: PAULO. Jacks Richard de. A formação de professores de Geografia: contribuições para mudança de concepção de ensino. Judiaí: Ed. Paco Editorial, 2016.

BORDALO, Carlos Alexandre Leão. O desafio das águas numa metrópole amazônida: uma reflexão das políticas de proteção dos mananciais da região metropolitana de Belém-PA (1984-2004). Tese (Doutorado). Programa de Pós-Graduação em Desenvolvimento Sustentável do Tropico Úmido, Núcleo de Altos Estudos Amazônicos Universidade Federal do Pará, Belém, 2006. 281 f.

O paradoxo da água na Amazônia. IN: Christian (Org). Produção do espaço e territorialidade na Amazônia paraense: elementos para análise geográfica. Belém: Ed. GAPTA UFPA, 2016.

CABRAL, Natalina Tinôco; LIMA, Liliane Maia. Qualidade da Água do Aquífero Barreiras em Bairros de Belém/PA. Águas Subterrâneas, v. 19, n. 2, p. 37-53, ano 2005. Disponível em: <https://aguassubterraneas.abas.org/asubterraneas/article/view/8226> Acessado em 22/05/2016.

CALVALCANTI, Lana de Souza. Ensino de Geografia e diversidade: construção de conhecimentos geográficos escolares e atribuição de significados pelos diversos sujeitos do processo de ensino. IN: CASTELLAR. Sonia. Educação Geográfica: teorias e práticas docentes. São Paulo: Ed. Contexto, 2005.

GUEDES. M. P. Por uma gestão das águas na "cidade das águas": uma análise geográfica da gestão dos recursos hídricos e dos serviços de abastecimento de água na cidade de Belém- PA (2008 a 2015). Dissertação (Mestrado em Geografia) - Universidade Federal do Pará, Belém, 2016.

Lei $n^{\circ}$ 5.731, de 15 de dezembro de 1992. Dispõe sobre a Organização Básica do Corpo de Bombeiros Militar Do Estado do Pará e dá Outras Providências. Disponível em:<www.pge.pa.gov.br/sites/default/files/repositorio/1992/lo5731.pdf.> Acessado em 10 de janeiro de 2017.

MATTA, Milton Antonio da Silva. Fundamentos Hidrogeológicos para Gestão Integrada dos Recursos Hídricos da Região de Belém / Ananindeua Pará - Brasil. Tese de Doutorado, UFPA, 2002.

NETO, Miguel Elias de Souza. Manual Prático com fórmulas de saneamento básico. Belém: Ed. Sindicato dos Engenheiros no Estado do Pará, 2009. 
Organização das Nações Unidas. ONU. Relatório de Desenvolvimento Humano - A água para lá de escassez: poder, pobreza e a crise mundial da água. Disponível em: www.portalodm.com.br/.../1/relatório-de-desenvolvimento-humano-brasil-2006.pdf. Acessado em 27/02/2017.

PAULO, Jacks Richard de. A formação de professores de Geografia: contribuições para mudança de concepção de ensino. Ed. Paco editorial, Judiaí, 2016.

RIBEIRO. Wagner da Costa. Geografia Política da Água. São Paulo: Ed. Annablume, 2008. p. 13-52;

RAVENA, Nírvia. Os caminhos da regulação da água no Brasil: demiurgia institucional ou criação burocrática? Curitiba: Ed. Appris Ltda., 2012.

RIBEIRO, Wagner da Costa. Geografia Política da Água. São Paulo: Ed. Annablume, 2008.

RAFFESTIN, Claude. Por uma Geografia do Poder. Tradução de Maria Cecília França. São Paulo: Editora Ática, 1993.

SANTOS. Milton. A Natureza do Espaço: Técnica e Tempo, Razão e Emoção. $4^{\text {a }}$ Edição. São Paulo: Editora da Universidade de São Paulo,2012.

STRAFORINI. Rafael. Ensinar Geografia: o desafio da totalidade-mundo nas séries iniciais. IN: TOZY, Shirley Capela. Bacia Hidrográfica: Aspectos Teóricos e Conceituais. Da Teoria de Sistemas ao Geossistema. CAMINHOS E LUGARES DA AMAZÔNIA, UFPA, BELÉM, 2009. São Paulo: Ed. Annablume, 2004.

SETTI, Arnaldo Augusto.et. al. Introdução ao gerenciamento de recursos hídricos. Brasília: Agência Nacional de água, Agência nacional de energia elétrica, 2001. 328 p.

SIMONIAN, Ligia T. Políticas Públicas, Desenvolvimento Sustentável e Recursos Naturais em áreas de Reserva na Amazônia Brasileira. In: COELHO, Maria Célia; SIMONIAN FENZL, Norbert (Org.)Estado e Políticas Públicas na Amazônia: Gestão dos Recursos Naturais. Belém: Ed. CEJUP, 2000.

TOZY, Shirley Capela. Bacia Hidrográfica: Aspectos Teóricos e Conceituais. Da Teoria de Sistemas ao Geossistema IN: CAMINHOS E LUGARES DA AMAZÔNIA, UFPA, BELÉM, 2009.

UHLY, Esteven; SOUZA, Eliene Lopes de. A Questão da água na grande Belém. UFPA. Belém: Ed. Casa de Estudos Germânicos, 2004. 